I am indebted to Messrs. Imperial Chemical Industries Limited (Dyestuffs Group) for supplying the crystals used in this investigation.

Physics Department,

College of Technology,

Manchester, 1.

${ }^{1}$ Groth, P. H., "Chemische Krystallographie", vol. 4, p. 297.

'Robertson, J. M., J. Chem. Soc., 1195 (1936).

${ }^{3}$ Robertson, J. M., J. Chem. Soc., 219 (1937).

‘ Weibull, M., Z. Krist., 15, 234 (1889).

\section{Measurement of Thickness of Thin Films}

Tolansky has shown in a recent series of papers ${ }^{1}$ that interference fringes formed by multiple reflexion between highly reflecting surfaces can be applied with great effectiveness to the study of surface topography. Thus Tolansky has been able to detect abrupt changes of only $20 \mathrm{~A}$. in level in cleavage surfaces of mica. We have recently applied this technique to the determination of thickness of thin layers of gold, silica, collodion and 'Formvar', which are widely used for supporting and other purposes in electron microscopy.

A typical sample of the appropriate thin film is, in preference, prepared in contact with a smooth glass surface. The film is arranged to cover only a part of the plate so that an abrupt step of depth equal to the thickness of the film is present at some position on the surface. Such a step may be formed by any appropriate method, for example, by shading part of the glass plate in the case of films formed by evaporation or by using the natural boundary of a portion of film in the case of plastic films. The composite surface thus formed is coated with a thin layer (300-400 A. say) of silver by evaporation in vacuo, and the silvered film placed in substantial contact with a similarly silvered second glass plate. Fizeau fringes are formed by the plates by using a collimated, filtered beam $(\lambda=5460)$ from a highpressure mercury-vapour lamp (Metrovick ME 250). The localized fringes are viewed in transmission with a low-power microscope and show in general smooth contours broken by an abrupt shift occurring at the film boundary. Fringe shifts of 1/200 of an order can be detected (that is, about $15 \mathrm{~A}$. in film thickness), and thus the method is suitable for the measurement of films of thickness $100 \mathrm{~A}$. and above.

The nature of the glass plates used in the apparatus merits some attention. Good quality sheet glass (for example, a lantern slide cover) proves particularly suitable, and indeed for smoothness of contour shape is superior to good quality optically worked glass. The reason for the superiority of sheet glass in this respect is presumably due to a small-scale smoothness of surface in 'fire-polished' glass that, as was anticipated, was absent in mechanically polished glass.

A typical photograph is reproduced of the fringe shift associated with a collodion film $390 \mathrm{~A}$. thick. We have successfully applied a similar technique to the measurement of evaporated films of silica and gold

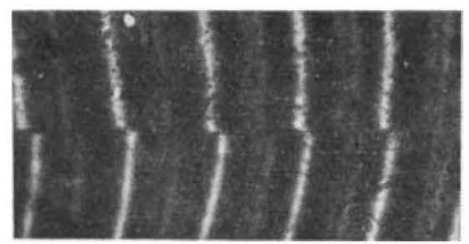

(using reflected fringes in the latter case), and we have also measured the optical thickness and consequently the refractive index of silica and collodion films.

High Voltage Laboratories,

A. F. GUNN

R. A. SCOTT

Metropolitan-Vickers Electrical Co., Manchester.

${ }^{1}$ Tolansky, Proc. Roy. Soc., 184, 41 (1945) ; 186, 261 (1946) and earlier papers.

\section{Phase-Contrast Microscopy for Mineralogy}

Phase-contrast microscopy has in recent years been applied to a number of biological problems ${ }^{1,2,3}$, but up to the present no results of its application to mineral substances appear to have been published. I recently suggested to Messrs. Cooke, Troughton and Simms, Ltd., that as they were preparing phasecontrast equipment for biological work, it would be of interest to determine whether the same methods would be of value in micro-mineralogy. As a test, they kindly allowed me to examine by this method some of my mineralogical slides, and from some they prepared photomicrographs.

In thin sections, the structures of rocks containing colourless minerals of similar refractive indices (for example, quartz and the felspars) showed up very clearly with phase contrast ; in these cases a further improvement in the image sometimes resulted from the use of a single 'Polaroid' filter placed in the beam. In Canada balsam mounts of china clays, the shapes of the larger particles were clearly seen. The photomicrographs reproduced here are sufficient indication that the technique represents a development which the mineralogist ought not to neglect.

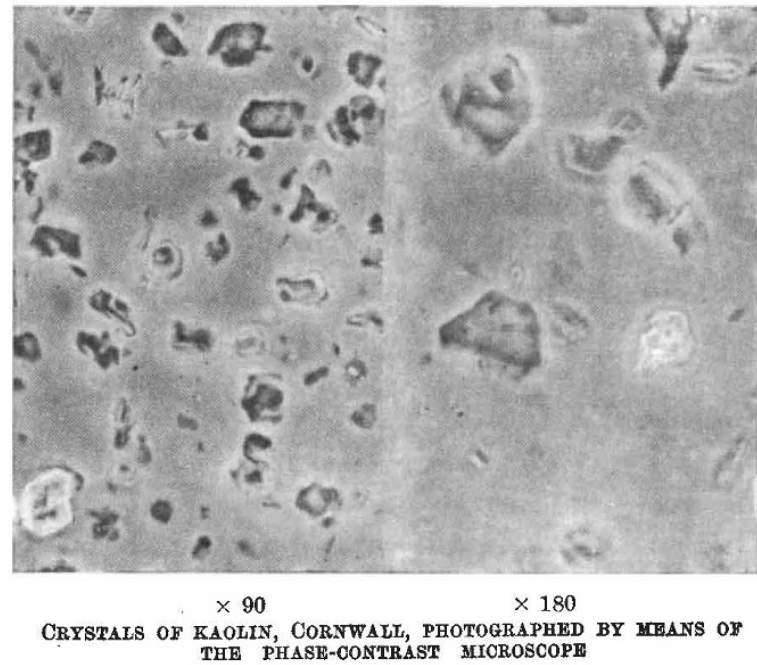

The phase-contrast equipment used in the above work consisted of a special condenser with annular diaphragms and a set of four objectives, giving magnifications of $10,20,40$ and 95 , each with its integral phase plate. The photographs reproduced above were taken with the lower-power objectives and a $12 \times$ eyepiece.

20 Queens Road, Hartshill,

F. SMIthson Stoke-on-Trent.

${ }^{1}$ Burch, C. R., and Stock, J. P. P., J. Sei. Instr., 19, 71 (1942).

${ }^{2}$ Richards, O. W., Nature, 154, 672 (1944).

Brice, A. T., Jones, R. P., and Smyth, J. D., Nature, 157, 553 (1946). 